
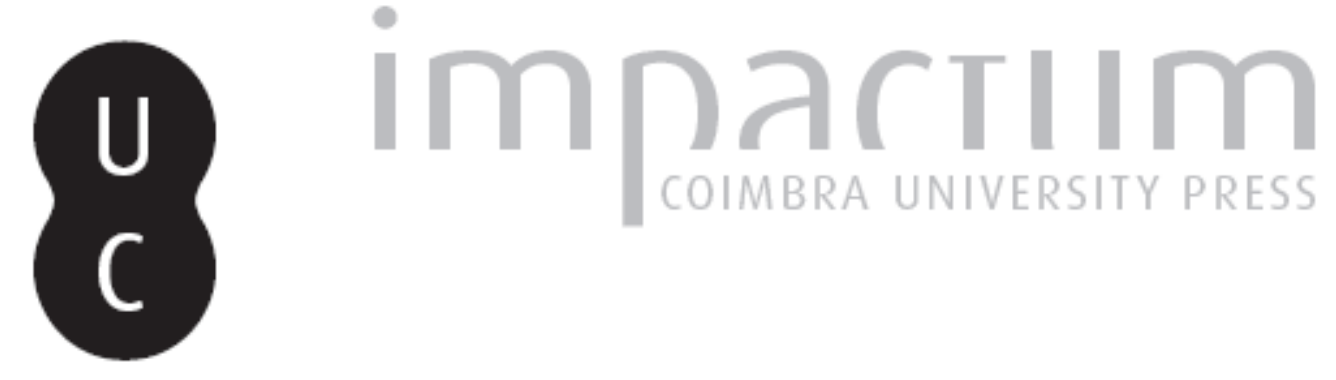

\title{
Constitucionalismo, estratégia insurrecional e internacionalismo liberal en la lucha contra el Antiguo Regimen español (1823-1831)
}

Autor(es): $\quad$ Castells Olivan, Irene

Publicado por: Imprensa da Universidade de Coimbra

URL persistente:

URI:http://hdl.handle.net/10316.2/43787

DOI:

DOI:https://doi.org/10.14195/2183-8925_10_28

Accessed : $\quad$ 26-Apr-2023 11:03:23

A navegação consulta e descarregamento dos títulos inseridos nas Bibliotecas Digitais UC Digitalis, UC Pombalina e UC Impactum, pressupõem a aceitação plena e sem reservas dos Termos e Condições de Uso destas Bibliotecas Digitais, disponíveis em https://digitalis.uc.pt/pt-pt/termos.

Conforme exposto nos referidos Termos e Condições de Uso, o descarregamento de títulos de acesso restrito requer uma licença válida de autorização devendo o utilizador aceder ao(s) documento(s) a partir de um endereço de IP da instituição detentora da supramencionada licença.

Ao utilizador é apenas permitido o descarregamento para uso pessoal, pelo que o emprego do(s) título(s) descarregado(s) para outro fim, designadamente comercial, carece de autorização do respetivo autor ou editor da obra.

Na medida em que todas as obras da UC Digitalis se encontram protegidas pelo Código do Direito de Autor e Direitos Conexos e demais legislação aplicável, toda a cópia, parcial ou total, deste documento, nos casos em que é legalmente admitida, deverá conter ou fazer-se acompanhar por este aviso.

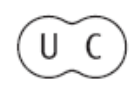


REVISTA DE HISTORIA DAS IDEIAS IO
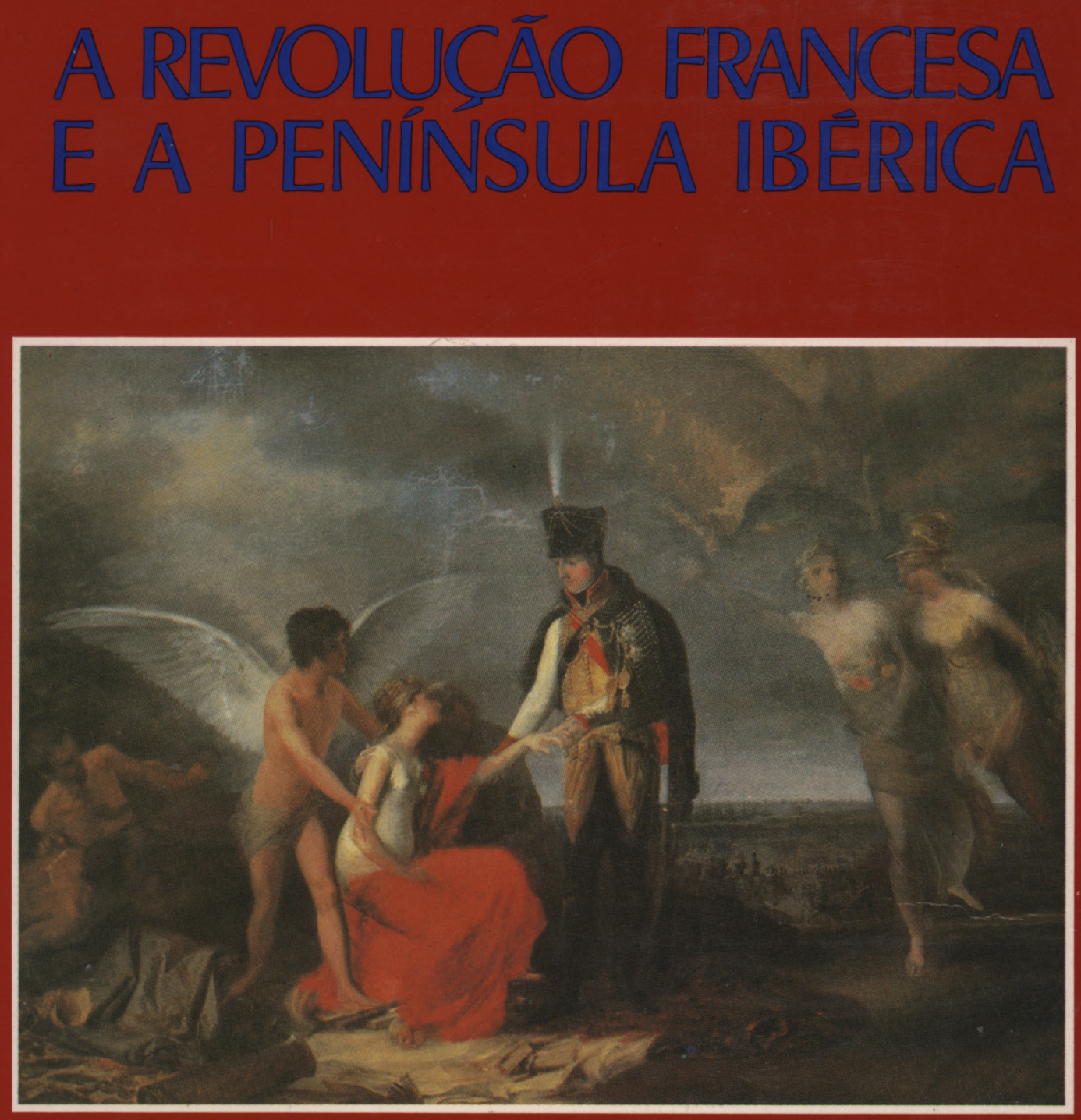

INSTITUTO DE HISTÖRIA E TEORIA DAS IDEIAS FACULDADE DE LETRAS 


\section{CONSTITUCIONALISMO, ESTRATEGIA INSURRECCIONAL E INTERNACIONALISMO LIBERAL EN LA LUCHA CONTRA EL ANTIGUO REGIMEN ESPAÑOL (1823-1831)}

\section{Introducción}

En la lucha entablada entre el Antiguo Régimen y la Revolución, los años 1823-1831 se caracterizan por una mayor radicalización de la reacción conservadora de los gobiernos europeos frente a los cambios políticos y sociales producidos por la revolución francesa y las guerras napoleónicas. El impacto de estos acontecimientos en la atmósfera política de la Restauración, se reflejaba en la idea existente de que la revolución en un país cualquiera podía convertirse en un fenómeno europeo. Ello explica el pánico de la Santa Alianza al contagio revolucionario y su intervención militar contra los regímenes liberales de 1820 en Italia y España. Este endurecimiento de las fuerzas reaccionarias, agravó las contradicciones de unos sistemas políticos caducos e inadecuados a las circunstancias históricas de un período sometido a rápidas transformaciones económicas y sociales. La revolución francesa de 1830 puso esta situación de manifiesto, y su triunfo asestó un golpe definitivo a la Europa dominada por la Santa Alianza.

Dentro del campo revolucionario, se partía de unas negativas condiciones de represión y exilio creadas por el violento final de la experiencia liberal de 1820-1823. Al mismo tiempo, la unidad liberal que había caracterizado eficazmente el período $1815-1820$, se resquebrajó en el breve período de tiempo que los liberales estuvieron en el poder, apareciendo las divisiones y tendencias que hay que incluir en la razones del fracaso de los regímenes constitucionales de 1820 en Italia, Por-

* Universidad Autónoma de Barcelona. 


\section{Revista de História das Ideias}

tugal y España. Las sociedades secretas que los exiliados europeos reorganizaron en la emigración, son buena prueba de la permanencia de estas divergencias y de la desorientación que afectó al movimiento liberal en la década de los años $20{ }^{1}$ ). Sin embargo, también es cierto que la intransigencia de la reacción y el decidido propósito que tenían los emigrados liberales de recuperar el poder que se les había arrebatado por la fuerza, les empujó a dejar a un lado las viejas polémicas y divisiones entre moderados, demócratas, vintistas o exaltados, en aras de la unidad de acción. Fue en definitiva el proyecto conspirativo e insurreccional lo que determinaba los acuerdos y coincidencias entre unas $u$ otras sociedades, pasando la línea de demarcación entre las mismas, por una mayor o menor confianza en las posibilidades de recuperación del movimiento revolucionario.

Esta necesidad de lograr un acuerdo común que evitase las discordias, encontró su punto de confluencia en el constitucionalismo: la reimplantación de la Constitución se convirtió en objetivo político, instrumento de movilización y contenido programático de la revolución que querían llevar a cabo. La concreción en una monarquía constitucional que diera la representación nacional a las élites - aristocracia liberal y burguesia -, fue la estrategia que se trazó la oposición liberal entre 1815-1820 , para conseguir una transición pacífica del antiguo al nuevo régimen y evitar los radicalismos de la revolución francesa. Después de 1820 , la viva discusión que había surgido sobre las fórmulas concretas de gobierno, queda postergada en el plano de la estrategia revolucionaria $\left({ }^{2}\right)$ en beneficio de una genérica lucha por un régimen Constitucional, que permitiera a los liberales derrocados reconquistar fácilmente el poder. Pero, por otra parte, esta simplificación de objetivos en torno a la Constitución exigirá para imponer el necesario cambio político la aplicación de una fórmula insurreccional adecuada a sus objetivos y que, por lo demás, había demostrado su eficacia: el pronunciamiento militar $\left({ }^{3}\right)$, cuya viabilidad e internaciona-

(1) Para la reorganización de las sociedades secretas después de 1823, ver A. Lehning, De Buonarroti a Bakounine, París, Editions Champ Libre, 1977, pp. 45-76.

(2) Sin embargo, en el terreno de las ideas, S. Mastellone, Storia ideologia d'Europa da Sieyès a Marx, (1789-1848). Sansoni, Bolonia, 1974, pp. 191-194, subraya la importancia del exilio liberal de estos años en la historia cultural europea, no sólo por el vehículo de ideas y opiniones que supuso el trasiego de la emigración política, sino también por las discusiones teóricas que se mantuvieron en su seno en torno a las fórmulas políticas de gobierno.

(3) Queda claro, que al calificar de militares los pronunciamientos liberales de la época, no considero a los mismos como un fenómeno 


\section{Constitucionalismo, Estrategia Insurreccional}

lización en 1820, hizo que se mantuviera vigente como técnica de subversión hasta las revoluciones de 1830. El exilio liberal, adaptando el modelo a su nueva situación, se ajustó fielmente al correspondiente esquema insurreccional, según el cual, al hecho del pronunciamiento sucede como un reguero de pólvora el alzamiento de diferentes núcleos urbanos por todo el país. $\mathrm{Ni}$ se trataba de una conquista, ni la insurrección tenía que ser violenta, sino que la mera presencia insurreccional de un jefe militar que hiciese el gesto del levantamiento en cualquier punto del país, bastaría para desencadenar el mecanismo de la sublevación.

Los liberales europeos de la década de los 20, seguían por tanto ateniéndose, en sus líneas generales, a la estrategia revolucionaria acuñada por las revoluciones de 1820: imponer la constitución mediante el pronunciamiento insurreccional, con el apoyo organizativo de las sciedades secretas de corte carbonario. Desde 1820 hasta la oleada revolucionaria de 1830, a estas características se unirá otro componente esencial: el internacionalismo. La colaboración en la formación de planes insurreccionales conjuntos, es una constante en la trayectoria conspirativa. La coordinación del pronunciamiento ya no afectaba sólo a la geografía urbana de un país, sino que se organizaban movimientos simultáneos en zonas alejadas unas de otras, pensando siempre en el mismo efecto acelerador, desde el punto de vista político, que pudiera producir el éxito de una o varias tentativas.

Existía una razón objetiva que explicaba y generaba la solidaridad existente entre el coniunto del movimiento revolucionario: el intervencionismo militar y político de las grandes potencias había sido determinante en la reciente derrota de 1820-1823. Apareció claro desde entonces, que sólo un cambio en la correlación de fuerzas a escala internacional podía favorecer las respectivas revoluciones nacionales. La defensa del régimen constitucional español, ya había expresado en la práctica esta «santa alianza de los pueblos», que hacía fuese una sola la causa de españoles, italianos, portugueses, franceses e independentistas iberoamericanos, la del pueblo griego y la de los decembristas rusos. Este movimiento patriótico europeo no tenía nada que ver con la supuesta «conjura internacional» denunciada por los agentes absolutistas, incapa-

estrictamente militar, saliendo al paso de la polémica historiográfica existente al respecto $y$, que a mi juicio, está mal planteada. El componente militar es un aspecto esencial de la estrategia política que el pronunciamiento supone como fórmula de subversión al servicio del liberalismo de la época. 
ces de ver las causas reales de los problemas sociales y de entender por tanto la complejidad del mundo sectario ce estos años (4).

Fueron en definitiva los procesos internos los que decidieron en cada país la suerte respectiva de los liberales europeos. Pero ello no fue evidente hasta la revolución de 1830 , que reorganizó el panorama político europeo e introdujo cambios decisivos en la estrategia de los movimientos revolucionarios $\left(^{5}\right)$.

En mi investigación sobre las conspiraciones liberales españolas de la llamada "ominosa década» (1823-1833), he podido verificar cómo los elementos señalados (constitucionalismo, pronunciamiento insurreccional e internacionalismo), son tres ejes fundamentales que ordenan y explican las actividades conspirativas entre 1823-1831, no sólo en el contexto español sino también en el marco europeo $\left({ }^{6}\right)$. En la presente comunicación, me propongo, al hilo de la trayectoria conspirativa de los liberales españoles exiliados, en cuya explicación no entro ahora, concretar los planteamientos generales que acabo de exponer y seguir la incidencia que, en la estrategia revolucionaria española, tuvieron las relaciones con liberales de otros países, centrándome en dos casos especialmente relevantes: en los contactos con el liberalismo portugués y en los que tuvieron lugar con los independentistas hispanoamericanos.

\section{Liberales españoles y portugueses: la Unión Ibérica}

La colaboración entre el liberalismo español y portugués y su plasmación en el "movimiento iberista», arranca de la experiencia constitucional de 1820-1823 en ambos países y de las relaciones y contactos llevados a cabo antes de que los respectivos pronunciamientos de 1820 consiguieran imponerse durante tres años frente al absolutismo peninsular $\left(^{7}\right)$. En lo que

(4) He desarrollado estas cuestiones en la comunicación "Liheralismo v sociedades secretas en la Europa de la Santa Alianza, 1823-1830", presentada en el Coloquio organizado por la Universidad de Cádiz. en abril de 1987. sobre el tema Ideas v movimiontos clandestinos, 3er encuentro de La ilustración al Romanticismo, 1750-1850. Labor, 1980 .

(5) E. J. Hobsbawm, Las revoluciones burguesas, Barcelona,

(') I. Castells, La utopia insurreccional: Las conspiraciones libe rales en el sur de España durante la "ominosa década", 1823-1831, tesis doctoral presentada en la Universidad Autónoma de Barcelona en junio de 1981.

(7) Da noticias de estos contactos J. Del Moral Ruiz, "La penetración del liberalismo en Portugal, 1814-1834», La prensa en la revolu- 
respecta a Portugal, el iberismo se vincula en principio al liberalismo radical y se desarrolla después del triunfo de la revolución española de 1820, cuando la crisis simultánea del imperio luso-brasileño y de la alianza inglesa, reforzó la idea de una posible unión con España como medio de hacer frente común a la dependencia de los intereses de las grandes potencias que pesaba sobre el liberalismo ibérico $\left(^{8}\right)$.

Pero, como es sabido. la intervención francesa en España en abril de 1823 contra el régimen constitucional, reforzó en Portugal a los absolutistas y llevó a los sectores más conservadores a apoyar el golpe contrarrevolucionario de la Vilafrancada. con la idea de substituir la Constitución de 1822 por un constitucionalismo extremamente moderado mediante el sistema de "carta otorgada». Este pactismo con las fuerzas del antiguo régimen existió igualmente en el régimen liberal español, aunque con características distintas, y explica en parte su derrota. Las debilidades y divisiones internas de ambos liberalismos, costaron diez años de exilio y represión a los españoles, y en Portugal, aunque se implantó primero un régimen de absolutismo atemperado (1823-1826) y otro constitucional después (1826-1828). se produio una violenta restauración absnlutista con el régimen despótico de Miguel I en 1828, originándose una lucha civil que no finalizaría hasta 1834.

Todos estos acontecimientos incidieron lógicamente en la trayectoria del iberismo $\left({ }^{\circ}\right)$, y si bien éste fue instrumentalizado desde 1826 en favor del emperador del Brasil, D. Pedro de Braganza, tuvo también su manifestación más auténtica en la conspiración conjunta de españoles y portugueses para restablecer el liberalismo en la Península.

La historia de esta lucha comienza desde los primeros momentos del exilio en 1823, pues aunque en Portugal no se

ción liberal, España, Portugal y America Latina, Madrid, Universidad Complutense, 1983, pp. 31-36.

(8) V. Alexandre, «O nacionalismo vintista e a questão brasileira: esboço de análise política», in $O$ Liberalismo na Península Ibérica na primeira metade do século XIX, I, pp. 287-307, donde explica la vinculación del iberismo a la ideología nacionalista de los "regeneradores» como Fernandes Tomás, frente a la postura mantenida por la derecha liberal portuguesa, que apoyó la contrarrevolución absolutista en 1823 y jugó la carta de la unión dinástica de Portugal y Brasil en torno a la dinastía de Braganza.

(9) Trayectoria que he abordado fundamentalmente en esta comunicación, desde el ángulo del liberalismo español y, sobre todo, como manifestación destacada del internacionalismo liberal de la época, pero que pediría una mayor investigación que tuviera en cuenta las fuentes portuguesas. 


\section{Revista de História das Ideias}

produjo entonces la violencia represiva que caracterizó los primeros años de la segunda restauración absolutista en España, no faltan testimonios de que la situación entre 1823-1826 recordaba la existente antes de 1820 , en lo que se refiere a la censura ideológica y a la persecución de liberales destacados durante el régimen derrocado $\left({ }^{10}\right)$. Aún así, Lisboa se convierte en refugio de liberales españoles y carbonarios italianos, y la policía denuncia ya a finales de 1825 la existencia de sociedades secretas que mantenían estrechos contactos con los exiliados españoles, los cuales tenían gran influencia en los medios profesionales y comerciantes de Oporto, desarrollando de manera conjunta una activa propaganda de los principios liberales ( $\left.{ }^{11}\right)$. Igualmente, el embajador español en París, Duque de Villahermosa, informaba en marzo de 1826, la existencia en la capital portuguesa de un club revolucionario hispano-lusitano,

"que se apoya en la esquadra Inglesa estacionada en el Tajo, a cuyo bordo permanece más de 15 meses el abogado Genovés, que es el director de aquella trama y que comunica frecuentemente con los del interior y con los de Londres» (12).

En Inglaterra estaban, efectivamente, los dirigentes de la conspiración española en el exilio, cuyo líder indiscutido fue hasta 1825 el general Espoz y Mina, quien tenía establecida, ya en 1824, una red clandestina de información para la organización del pronunciamiento insurreccional en España, cuyos comisionados principales estaban en Gibraltar, Lisboa y Oporto $\left({ }^{13}\right)$.

Las relaciones con el liberalismo portugués pasaron al primer plano de las actividades conspirativas de los exiliados españoles, cuando, a la muerte de Juan VI en marzo de 1826,

(10) G. Boisvert, Un pionnier de la propagande liberale au Portugal: João Bernardo da Rocha Loureiro (1778-1853), Fundação Calouste Gulbenkian, Centro Cultural Portugues, París, 1982, v. 199.

(11) J. Del Moral Ruiz, "La penetración del liberalismo en Portugal....», pp. 34-35, nota 6 , donde indica que la correspondencia de Espoz y Mina con sus agentes en Portugal está en el Archivo Histórico Nacional da Torre do Tombo de Lisboa, en Intendencia de Policía.

(12) Archivo Histórico Nacional de Madrid (A.H.N.), Estado, legajo 3075 .

(13) Véase J. Puyol, La conspiración de Espoz y Mina (1823-1830), Madrid, 19.32. v náfina 285 de TM. Zavala. Masones, comuneros $y$ carbonarios, Madrid, Siglo XXI. 1971, correspondiente al informe de Regato, agente de policía de Fernando VII, Resumen histórico. de las maauinaciones $v$ tentativas revolucionarias de los esnañoles emigradns en Inglaterra, Francia y Gibraltar, sacado de noticias dadas en difenentes épocas por diversas personas, desde principio de 1824. hasta fines de julio de 1830, publicado integralmente en las páginas 279-300. 
su primogénito, el emperador del Brasil, fue aclamado rey en Portugal como Pedro IV, abdicando inmediatamente a favor de su hija de siete años Maria de la Gloria, con la condición de que se casara con su tío Miguel, al cual se le confiaba la regencia del reino. Al mismo tiempo, D. Pedro otorgó en abril a Portugal una Carta Constitucional, que establecía un régimen liberal conservador. La incidencia de este hecho en la estrategia revolucionaria del liberalismo español, cobra varios aspectos. En primer lugar, Portugal aparece como la plataforma necesaria, cercana a la patria, que permite organizar desde un país amigo, la incursión en tierra española para iniciar la sublevación. Esta perspectiva convenció a muchos emigrados de la inminencia del éxito insurreccional, y culparcn a Mina de su pasividad respecto a la organización del mismo, al verle centrar su actividad en negociaciones diplomáticas con el gobierno inglés de cara a conseguir su apoyo para la causa liberal en España.

En segundo lugar, y aunque la animadversión respecto al general ya había sido manifiestada anteriormente por el grupo comunero ligado a Romero Alpuente, Bertrán de Lis y Alvaro Flórez Estrada, que consideraban al general como «incapaz de hacer nada por la causa de la libertad», sin embargo la efervescencia creada por la nueva situación portuguesa cuajó en febrero de 1827 en la creación del otro núcleo que dirigió la conspiración liberal desde Inglaterra: el formado en torno al militar José María de Torrijos.

Por último, los liberales exiliados españoles. que juzgaban, desde 1823, incompatibles a los Borbones de España con el establecimiento de un régimen representativo, llegando incluso a ofrecer la corona a José Bonaparte, encontraron en D. Pedro de Braganza el monarca idóneo para encarnar la Unión Ibérica uniendo los dos reinos bajo una Monarquía constitucional moderada. Y a partir de 1826, el emperador del Brasil empezó a recibir diversos mensajes que le instaban a que aceptase la propuesta (14).

Mientras tanto, revolucionarios italianos y españoles marchan a Portugal «con la idea de armar una como en el 20» $\left({ }^{15}\right)$.

(14) Gil Novales, "Repercusiones españolas de la Revolución de 1830", Anales de Literatura Española, Universidad de Alicante, n. 2 , 1983 , pp. 281-328, donde da la noticia del envío de varios mensajes a D. Pedro por parte de varias Juntas y sectores de exiliados liberales españoles.

(15) Archivo General de Simancas (A.G.S.), Estado, Documentos relativos a Inglaterra, legajo 8.189, folio 69: informe de la confidenta Vicenta Oliete al embajador español en Londres, conde de Alcudia, en noviembre de 1826. 


\section{Revista de História das Ideias}

Los españoles proceden en su mayor parte de Gibraltar y de Inglaterra, a pesar de que el embajador portugués en Londres, el marqués de Palmela, no facilicitaba su traslado $\left({ }^{16}\right)$. Muchos de ellos, la mayoría militares, consiguieron sin embargo, desde agosto de 1826, llegar a tierra lusitana, donde fueron en principio bien recibidos, si bien se organizaron depósitos para acogerlos bajo ciertas condiciones y garantías $\left({ }^{17}\right)$. Espoz y Mina y Torrijos envían también sus comisionados para dirigir las actividades conspirativas de la Junta hispano-lusitana que se formó en Lisboa $\left({ }^{18}\right)$, y entre septiembre de 1826 y febrero de 1827 , se organizan varias expediciones para penetrar desde Portugal en varios puntos de España $\left({ }^{19}\right)$, aunque ninguna llegó a realizarse.

Lo imprevisto de los acontecimientos portugueses, impidió que los dirigentes de la conspiración liberal española tuviesen tiempo de poner en pie unos planes insurreccionales mejor organizados. Los jefes militares principales seguían en Londres, absorbidos por los contactos diplomáticos o por la reorganización que se estaba produciendo en las propias actividades conspirativas. $Y$ era necesario que un militar de prestigio encabezase el pronunciamiento. Así lo expresaba un tal Pedro Morear, comunero español ligado al grupo de Romero Alpuente, en una carta que le escribía a éste, el 20 de febrero de 1827, desde el depósito de Santarém, a catorce leguas de Lisboa, instándole a que abandonase Londres:

«En este depósito habremos como 400 Españoles entre oficiales y tropa, y no se los que habrá en el de Oporto, ni en el de otros dos más depósitos formados nuevamente en pueblos de la frontera que no me acuerdo sus nombres. Cada día se pasan de España oficiales y tropa y todos, como las cartas que se reciben, está conforme con que el espíritu de la Nación está para estallar. No creo que haya un buen Español en ésa, que en el momento de saber la

(16) A.G.S., Estado, legajo 8.189, folio 122: informe del conde de Alcudia del 2-VIII-1826.

(17) R. Marrast, José de Espronceda et son temps, Klincksieck, Fontenay-Le-Comte, 1974, pp. 135-136.

(18) Florentino Arizcun, como principal de Mina, y José de Coba y Manuel Núñez, entre los enviados de Torrijos.

(19) Entre otras, la expedición organizada al Algarve, notificada por el embajador español en Lisboa en octubre de 1826 y por el de Londres en diciembre del mismo año, para entrar por Ayamonte y unirse con los llegados de Gibraltar (A.G.S.), Estado, legajos 8.189 y 8.229), y la preparación, también desde Portugal, del estallido insurreccional en Cáceres, denunciado por Vicenta Oliete en febrero de 1827, (A.G.S., Estado, legajo 8.190, folio 42). 


\section{Constitucionalismo, Estrategia Insurreccional}

protección y auxilio de este benéfico Gob. , deje de venirse.... Su falta de Vd. en la capital de este Reyno, la de Valdés, Rotalde, Pinto, y otros buenos amigos, trayéndose consigo al General Milans, sin duda mejoraría y activaria el estado de cosas, en disposición que a últimos del venidero Marzo, o principios de Abril, podríamos estar en España dando palos; con que así, en Vds. consiste el que podamos tener patria....» $\left({ }^{20}\right)$.

El momento aparecía efectivamente como explosivo. Los absolutistas portugueses se habían refugiado en España organizando a su vez partidas que actuaban en Portugal, lo que obligó a establecer una comisión para el internamiento respectivo de españoles y portugueses en Portugal y España (21). Aunque el ministro británico Canning utilizó en un principio a los refugiados españoles como posible fuerza explosiva en la frontera hispano-portuguesa, no tenía intención alguna de declarar la guerra a España, contrariamente a lo que creyeron los liberales españoles. Estos saludaron con júbilo la noticia del envío de la ayuda militar inglesa a Portugal, en enero de 1827. Era sin embargo sólamente una respuesta puntual del gobierno inglés a la intervención de Fernando VII en favor de los miguelistas portugueses, con la invasión del general Longa (22). España tuvo que destituir a éste y conservar su neutralidad, debiendo conformarse con el envío de un ejército de observación a la frontera portuguesa, cuya presencia aprovecharon los españoles de Portugal para hacer propaganda entre soldados y oficiales.

Desde la primavera de 1827, el creciente desinterés de Francia e Inglaterra por los asuntos portugueses $\left({ }^{23}\right)$, benefició a los partidarios del gobierno absoluto de D. Miguel. El principal comisionado de Torrijos en Lisboa, Manuel Nuñez de Arenas, criticaba por estas fechas el hecho de que se siguiera invirtiendo más tiempo en estériles negociaciones, cuando era un momento propicio para la acción, teniendo los españoles que confiar solamente en sus propias fuerzas $\left({ }^{24}\right)$. La situación fue empeoran-

(20) A.G.S., Estado, legajo 8.190 , folio 59, citado también por Ch. Lancha, Alvaro Florez Estrada, 1766-1853, París, Ellug, 1984, pp. 198 y $292-293$.

(21) A.G.S., Estado, legajo 8.191, folio 23.

(22) Véase L. Fernandez Martin, El general don Francisco de Longa y la intervención española en Portugal, 1826-1827, Bilbao, Junta de cultura de Vizcaya, 1954.

(23) Ver A. Silbert, «La France et la politique portugaise de 1825 à 1830», $O$ Liberalismo...., I, pp. 41-61.

(24) L. Saenz de Viniegra, Vida del general don José Maria de Torrijos y Uriarte, Madrid, 1860, I, pp. 319-321. 
do para los refugiados españoles, que sufrieron detenciones y expulsiones, como la del propio Romero Alpuente, quien llegó finalmente a Lisboa el 13 de abril de 1827 para estar de nuevo en Inglaterra ocho días después $\left({ }^{25}\right)$.

Por su parte, los iberistas portugueses agrupados en torno al Ministro de la Guerra, general Saldanha - que fue depuesto de su cargo - y al médico Abrantes, conscientes de que ante la debilidad del régimen portugués, sólo la Unión Ibérica ofrecida a D. Pedro del Brasil, podría garantizar la supervivencia del liberalismo en Portugal, celebraron a finales de 1827 una entrevista con Espoz y Mina y Torrijos, ofreciendo a éstos la ayuda del comercio de Lisboa para la organización de los planes insurreccionales $\left({ }^{26}\right)$.

Fue también entonces cuando la «Asamblea de Constitucionales Europeos» o «Centro Universal de Actividad Patriótica», sociedad secreta ligada a las actividades de la Junta de Torrijos en Londres, decidió enviar un representante de la misma al Brasil para ofrecer una vez más a D. Pedro de Braganza el imperio de toda la Península ${ }^{27}$ ).

Se redactaron para tal fin unas «Bases sobre las cuales se han de formar las principales reglas para la ynstalación de un govierno provisional o interino, bajo el nombre de Regencia del Imperio o Reynos unidos de España y Portugal; a cuya cabeza o frente se ha de poner al actual Emperador del Brasil D. Pedro de Braganza, reynando bajo las condiciones que se estipularán» $\left({ }^{28}\right)$. En ellas se especificaba que la regencia se formaría en Londres, la cual nombraría la comisión que debía marchar al Brasil con instrucciones precisas «para ponerlas en conocimiento del Emperador, y reyterarle de nuevo el ofrecimiento que se le hace de ponerlo en posesión de las dos naciones o Reynos de España y Portugal y exigirle que de nuevo acepte la oferta, ofreciendo su auxilio como ya lo tiene echo, pero con las formalidades que la comisión crea necesarias y seguras, pero reservadas, haciéndolo con la mayor precaución

(25) A.G.S., Estado, legajo 9.190, folio 51: carta de Vicenta Oliete, sobrina de Romero Alpuente, al conde de Alcudia.

(26) A. Gil Novales, "Repercusiones....», p. 293. Cita entre los portugueses, además de Saldanha y Abrantes, al arzobispo de Elvas, al general Jorge Avilé y al conde de San Payo.

(27) A.H.N., Estado, legajo 3.075: informes de Cea Bermúdez desde Londres en enero de 1828, y del conde de Ofalia desde París en 1828 y en marzo de 1830 .

(28) A.H.N., Estado, legajo 3.075: documento sin fecha, enviado al gobierno español por su embajador en Londres, Cea Bermúdez, el 19 de agosto de 1830 . 
y sigilo». El documento explicitaba algunas de estas condiciones, como era la de que «Por ningún pretexto ni estilo serán admitidos en esta asamblea o representación de los dos Reynos ninguno de los que haya pertenecido a los Pasteleros o amasadores en la desgraciada época en que tubieron el mando (ecepto aquellos que desde el año 27 se hayan desengañado y combencido de las iniquidades, y maliciosa e inteligente apatía de sus principales amasadores)....». Salía a continuación en defensa de los liberales «llamados exaltados por el partido amasador», pero teniendo cuidado en especificar a continuación, con una evidente intención unitaria, que su deseo era, como el de la mayor parte de los españoles, «volver a sus casas con tranquilidad bajo el mando de un Govierno moderado».

En un documento posterior, en este caso de fuente portuguesa $\left({ }^{29}\right)$, aparece la justificación que el movimiento iberista hacía de los derechos de Pedro de Braganza a detentar la corona de dos reinos peninsulares, criticando al tiempo la actuación de los Borbones de España:

«El Sr. Dn. Pedro 4. , dando una Constitución al Brasil y otra a Portugal, ha unido positivamente su destino, nombre y gloria a la existencia de la justa libertad dada generosamente a una tercera parte de la Península. De este modo el Sr. Dn. Pedro $4 .^{\circ}$ atacó virtulamente el principio gubernativo que rige actualmente en España, y por consiguiente la existencia de Fernando 7. derechos de su dinastía... También Fernando 7.o no ignora que Portugal y España en la cuestión de independencia y libertad es una y sola causa, y que ambas hacen un solo cuerpo moral, y que así como Fernando ha unido su destino al principio absoluto de su Gobierno, el Sr. Dn. Pedro 4. ha unido también positivamente el suyo a la esencia del que mandó jurar....».

Se ignora el resultado de la embajada de 1827, en la que participó el comerciante español Sierra Mariscal, establecido en Lisboa y refugiado entonces en Inglaterra $\left({ }^{30}\right)$, pero tendría seguramente por parte de $\mathrm{D}$. Pedro, la misma respuesta vaga e imprecisa que las anteriores, evitando comprometerse pero cuidando de no perder la alianza de los liberales españoles,

(29) A.H.N., Estado, legajo 3.075: documento sin fecha enviado a Cea Bermúdez desde Rio de Janeiro en 1831.

(30) Su hermano, Alfonso Sierra Mariscal, se convirtió en enero de 1828 en un agente de la red de espionaje del conde de Ofalia, para informar de todo lo concerniente a la «Asamblea de Constitucionales Europeos" y de las actividades de su secretario, el granadino Juan Rumí: A.H.N., Estado, legajo 3.075, y A.G.S., Estado, legajo 8.196. 
más necesaria aún desde que $\mathrm{D}$. Miguel se había proclamado en Portugal rey absoluto en julio de 1828 .

Miles de portugueses se ven obligados a buscar refugio en Inglaterra, donde Palmela, que recibe el dinero que el Brasil enviaba según los términos del tratado de paz de 1825, les distribuye las ayudas, pero de forma desigual y arbitraria $\left({ }^{31}\right)$. Los exiliados españoles organizaron entonces campañas de solidaridad para recoger fondos, en un contexto cada vez más desfavorable por parte del gobierno inglés respecto a los emigrados de la Península $\left({ }^{32}\right)$.

La nueva situación en Portugal produjo un reagrupamiento de fuerzas en torno a la defensa de la Carta, si bien el clan de Palmela apoyó incondicionalmente a D. Pedro, que aparecía como el hombre providencial, mientras el general Saldanha agrupaba a los llamados "partidarios de la Reina», $r \in t i c e n t e s$ respecto al emperador ${ }^{(33)}$. Los liberales españoles mantienen contactos con ambos: a Espoz y Mina, que también envió su comisionado al Brasil para entrevistarse con D. Pedro, le visitan tanto Palmela como el enemigo acérrimo de éste, João Bernardo da Rocha Loureiro ${ }^{(34}$ ). Los del grupo de Torrijos, más unidos con Saldanha, no pierden las relaciones con Palmela, esperando también la ayuda financiera del mismo. En 1829 aparecen sin embargo defraudados por las esperanzas puestas en el emperador D. Pedro. El embajador español en Londres informaba al respecto que

\begin{abstract}
«Don Pedro (emperador del Brasil), no mantiene relaciones tan íntimas con estos revolucionarios porque ha conocido que la grande opinión de que gozaba entre ellos ha decaído muchísimo al ver que no ha cumplido exactamente sus promesas y ofertas que les tenía hechas, pero no ha cortado enteramente sus relaciones con ellos porque tampoco ha renunciado a valerse de su auxilio en cuanto pueda serle útil para combatir la causa de Dn. Miguel en Portugal.... Ha ofrecido a la Asamblea dos millones de cruzados pagaderos en pedrerías $\mathrm{v}$ alajas que deben destinar a la empresa revolucionaria» (35).
\end{abstract}

(31) G. Boisvert, Un pionnier...., pp. 213-214.

(32) Saenz de Viniegra, Vida del general...., I, pp. 310-313. El primer ministro Wellington suspendió en julio de 1829 el subsidio que recibía Torrijos.

(33) G. Boisvert, Un pionnier..., p. 217.

(34) Idem, p. 218. El enviado de Mina a Rio de Janeiro era un tal Fernando Valiñane, residente en Lisboa en 1826-28, A.G.S., Estado, legajo 8.324.

(35) A.G.S., Estado, legajo 8.196, folio 3: informe del 3 de Julio de 1829 del embajador español en Londres. 
El apoyo económico de D. Pedro fue no obstante reiteradamente solicitado en los años siguientes por los liberales españoles, aunque nunca lograron conseguir los fondos necesarios para sus proyectos $\left(^{36}\right)$.

Además de estos contactos, la colaboración entre liberales de ambos países, se manifestó, en la existencia de sociedades secretas, en el seno de las cuales se formaron varios planes conspirativos conjuntos a lo largo de estos años. La más importante de ellas era la ya citada «Asamblea de Constitucionales Europeos», que tenía su sede en Londres y estaba formada por miembros españoles, portugueses, italianos, franceses, insurrectos americanos e ingleses. Había surgido hacia 1825 y mantuvo sus actividades hasta el otoño de 1829, ocupando los españoles Juan Rumi y Antonio Baiges el secretariado de la misma, presidiendo además la sección encargada de España $\left({ }^{37}\right)$. Las autoridades españolas absolutistas siguieron de cerca sus actividades, informando que pertenecían a ella los masones, comuneros y carbonarios, para «hacer una especie de fusión de las tres corporaciones o cofradías a que habían pertenecido en España, uniéndose en este proyecto con sus hermanos o cuñados de Italia y Portugal» $\left({ }^{38}\right)$. Desde ella se organizaron los contactos con el interior, el envío de propaganda y la discusión sobre en qué puntos se podría iniciar «un rompimiento simultáneo», es decir, la penetración en la Península por varios puntos a la vez para provocar la sublevación general.

Pero el otoño de 1829 fue un momento de reflujo para los liberales españoles. Aunque el embajador de España en Londres informaba en febrero de 1830 que Palmela había dado a Espoz y Mina «cien mil libras esterlinas para intentar un movimiento revolucionario en la Península, al tiempo que la expedición contra Portugal se lleva a efecto y distraer por este medio la atención del gobierno de S.M. que ellos suponen dispuesto a oponerse a sus planes en aquel Reyno» ${ }^{39}$ ), el general ya había renunciado a continuar organizando el pronunciamiento. Los de la Junta de Torrijos continuaron trabajando para el mismo, pero confesaban no encontrarse «con suficiente posivilidad para

(36) Sobre todo, cuando su llegada a Europa en el verano de 1831. Véase al respecto, A.H.N., Estado, legajo 3.075; L. Cambronero, Torrijos, Málaga, 1931, pp. 187-188; Espoz y Mina, Memorias, B.A.E., t. 147, pp. 210-211, y A. Gil Novales, "Repercusiones....», pp. 293-194.

(37) A.H.N., Estado, legajo 3.075.

(38) Aviso a los incautos sobre los ridiculos y vanos proyectos del llamado Centro Universal de Actividad Patriótica establecido en Londres (s.f.), p. 4.

(39) A.H.N., Estado, legajo 1.075. 
hacer ninguna tentativa contra Porugal, ni menos contra su Patria, por verse descuidados de los recursos que se necesi$\tan . . . \gg\left({ }^{40}\right)$. Por su parte, el hecho de que los portugueses hubiesen podido desembarcar en las playas de Terceira a comienzos de 1829 y conseguir el apoyo de la isla, les hizo desde entonces centrar sus esfuerzos en consolidar la plataforma liberal de las Azores para organizar desde allí la expedición a Portugal.

Entre septiembre y noviembre de 1829 , muchos de los antiguos miembros de las «Asambleas de Constitucionales Europeos», aparecen reunidos en una nueva sociedad llamada «Los Unidos contra los tronos y Clero, o los emprendedores de la anarquía» $\left({ }^{41}\right)$, la cual tenía ramificaciones en Francia, Países Bajos, España, Portugal e Italia. En sus sesiones se leían comunicados enviados por socios de la misma en dichos países. El de Italia decía estar allí bastante adelantados los trabajos revolucionarios pero advertía "que no deve tratarse de hacer ningún rompimiento sin antes saverse a punto fijo con la fuerza que se puede contar tanto en España como en Portugal e Italia, y luego saverse convinar un Plan general con el objeto de no llamar la atención por una sola parte». El delator que informaba de estas reuniones, daba también la noticia de la próxima asistencia a una reunión de la sociedad, de los portugueses Saldanha, Palmela y el Conde de Acuña, y de la puesta en pie de nuevos planes revolucionarios para la primavera de $1830{ }^{(42}$ ).

Lo cierto es que la revolución francesa de 1830 sorprendió a los revolucionarios españoles de la Junta de Londres en plena actividad. Los acontecimientos de Francia reorganizaron de nuevo la actividad conspirativa de los emigrados españoles, y las expediciones que iniciaron al interior de España desde la frontera de los Pirineos, volvieron a dar constancia del internacionalismo liberal con la presencia en sus filas de portugueses, italianos y franceses. Tras el fracaso de las mismas Torrijos y su grupo siguieron, desde Gibraltar, intentando sin éxito el pronunciamiento. La situación portuguesa seguía siendo la gran

(40) A.G.S., Estado, legajo 8.324.

(41) Idem, citada también por R. Marrast, José de Espronceda...., pp. 151-153 y nota 44 .

(42) A.G.S., Estado, legajos 8.234, 8.198 y 8.199, y A.H.N., Estado, legajo 3.075: en marzo de 1830, el conde de Ofalia comentaba estos contactos en los siguientes términos: "No tengo duda de que algunos revolucionarios españoles a cuya cabeza está Torrijos, reunidos con otros Portugueses, Italianos $\boldsymbol{y}$ Americanos, $\boldsymbol{y}$ apoyados por Ingleses radicales e liberales franceses, subsisten en sus maquinaciones contra nuestro gobierno y la tranquilidad de la Peninsula...... 
esperanza, y en enero de 1831 las autoridades absolutistas españolas denuncian de nuevo las conversaciones que tienen los $r \in$ fugiados españoles con Saldanha «para unirse algunos de ellos a la proyectada expedición que se supone ha de salir de Tercera para atacar a Portugal, lo que me parece verosimil y aun consiguiente, siendo unos mismos los intereses e ideas de ambos partidos» $\left(^{43}\right)$. La llegada de D. Pedro de Braganza a Europa en el verano de 1831, tras abdicar en Brasil a favor de su hijo Pedro II, unió de nuevo la causa de emigrados portugueses y españoles, ofreciéndole éstos sus servicios ${ }^{(44)}$. Torrijos solicitó por última vez su ayuda, antes del fracasado desembarco en Málaga, en diciembre de 1831, que le costó la vida. Espoz y Mina no pudo regresar a España hasta 1834.

D. Pedro, con el apoyo de Francia e Inglaterra, pudo finalmente organizar la expedición a Portugal, desembarcando cerca de Oporto en julio de 1832. Estaba convencido, de que ante la mera presencia de las tropas constitucionales en tierra portuguesa, los miguelistas depondrían las armas. Y efectivamente, los liberales entraron en la ciudad pocos días más tarde, casi sin derramamiento de sangre.

La estrategia insurreccional con eco en el pronunciamiento como modelo, tendría una tardía pero significativa confirmación en el éxito de Oporto, lo que no se logró en España.

\section{Relaciones de los liberales españoles exiliados con los independentistas hispanoamericanos}

La lucha de los liberales españoles y europeos durante el período 1823-1831, coincide con la última etapa independentista de los hispanoamericanos, en la que éstos trataban de lograr el reconocimiento diplomático de las potencias europeas y la plena soberanía de las nuevas naciones. Las rivalidades colo-

(43) A.G.S., Estado, legajo 8.237.

(44) The Hispanic Society of America, Colección Torrijos, "Cartas particulares dirigidas a D. Ignacio López Pinto y otros»: carta desde Gibraltar dirigida por Torrijos y Manuel Flores Calderón a Ignacio López Pinto, en julio de 1831, en el que encargaban a éste se entrevistase con $\mathrm{D}$. Pedro, recordándole el proyecto de los liberales españoles de trabajar conjuntamente por el restablecimiento de la libertad, y A.H.N., Estado, legajo 3.076: documento anónimo en que habla de los contactos entre Espoz y Mina y D. Pedro y la agitación que este suceso produio entre los emigrados españoles de París, dispuestos a reconocer a D. Pedro, "por rey de España y su libertador». También habla de su entrevista con D. Pedro, Espoz y Mina en sus Memorias, B.A.E., t. 147, pp. 209-210 
nialistas y la defensa ideológica del principio de legitimidad, hacían que la Santa Alianza se opusiese enérgicamente a la aceptación de su independencia, mientras que la doctrina Monroe formulada en diciembre de 1823 , apoyando la política británica, declaraba la hostilidad norteamericana a una empresa de reconquista de Hispanoamérica por la Europa de la Restauración.

En este contexto, es explicable que la ideología revolucionaria de la época, viera en el colonialismo una forma de opresión similar al despotismo absolutista, identificando los problemas de la emancipación de Iberoamérica con los de los países de Europa que luchaban por su libertad (45).

En el caso concreto de los liberales españoles, ya se había manifestado después de la primera restauración absolutista de Fernando VII en 1814, cómo algunos de ellos concebían íntimamente ligadas la lucha contra el absolutismo en España y la de liberación nacional en Hispanoamérica, considerando que el objetivo de la independencia era en realidad el de conseguir un gobierno constitucional $\left({ }^{46}\right)$. En el pronunciamiento de Riego de 1820, la idea de que si había revolución en España no se haría la campaña de América, fue utilizada en las proclamas de Riego y Quiroga para ganarse al ejército expedicionario que esperaba su embarque en Cádiz $\left.{ }^{47}\right)$. Y pese a la miopía y ambiguedad de la política colonial que llevó a cabo el régimen liberal español entre 1820-1823, empeñado en mantener la presencia española en Hispanoamérica, un sector minoritario del liberalismo, coincidente con su izquierda, se mostró más favorable a la emancipación, posición que se afianzó y ganó adeptos desde 1823, durante los años de exilio ${ }^{48}$ ).

Cuando Fernando VII restauró por segunda vez el absolutismo, incluso aquellos hispanoamericanos que habían sido

(45) A. Zviguilsky, "Los decembristas y la independencia de América Latina", Homenaie a Noel Snlomon, Barcelona, Universidad Autónoma de Barcelona, 1979, pp. 23-29.

(46) O.J.E. Rodriguez, El nacimiento de Hispanoamérica. Vicente Rocafuerte y el hisnanoamericanismo, 1808-1832, México, Fondo de Cultyra Ernnómica. 1975, pp. 42-43.

(47) J.L. Roca, «Las iniciativas de los liberales españoles para terminar la guerra en América (1820-1822), Historia boliviana, IV/2, Cochabamba. 1984. pp. 168-170.

(48) Véase al respecto, A. Gil Novales, «La independencia de América en la conciencia esvañola, 1820-1823», en Del Antiguo al Nuevo Régimen en Fspaña. Rihlintera de la Academia Nacional de la Historia, Caracas, 1986, pp. 125-157; Ch. Lancha, «La prensa liberal española frente al separatismo hispano-americano", La prensn liheral..... pp. 307-317. y J.R. Aymes, "F.1 anticnlnnialismo español (1788-1833), Historia 16, III, n. 21 , enero 1978, pp. $23-40$, 
partidarios de la unidad hispánica dentro de una estructura constitucional, desengañados por la actuación de las cortes españolas, estaban ya decididos a luchar por la independencia, convencidos de que sólo así lograrían un sistema representativo de gobierno. Eran éstos los llamados «hispanoamericanistas», profundamente influenciados por el liberalismo español, que consideraban a la América española como una sola unidad y que continuaron manteniendo una estrecha afinidad con los constitucionalistas españoles ( $\left.{ }^{49}\right)$. A ellos pertenecían José Mariano Michelena, Vicente Rocafuerte y Manuel Eduardo Gorostiza, que representaron en Londres los intereses del gobierno de Mexico, desde que, en 1824, llegaran los dos primeros a la capital británica con la misión de obtener el reconocimiento de Inglaterra y la intervención de este país como mediador en nombre de Mexico ante España. Allí entraron en contacto con los liberales españoles exiliados, e inmediatamente se inició la conspiración conjunta que se íba a mantener hasta 1830.

Aunque no fueron los únicos hispanoamericanos que colaboraron en la empresa insurreccional de los españoles, éstos mantuvieron con ellos una mayor relación, tanto por los antiguos lazos de la común experiencia liberal que les unían, como por el hecho fundamental de que los quiméricos planes de reconquista de Fernando VII, estuvieron centrados durante esos años en organizar desde Cuba una expedición para que desembarcara en Mexico y lo reintegrara al dcminio español $\left({ }^{50}\right)$. Españoles e hispanoamericanos tenían mútuo interés en la lucha contra el absolutismo fernandino. Los primeros esperaban que los independentistas les ayudaran a organizar su incursión en España, sabiendo que éstos, además de mantener esperanzas de que los liberales exiliados lograran abatir el absolutismo, se beneficiaban del entorpecimiento que sobre los planes de reconquista de Fernando VII suponía la existencia de sus planes conspirativos.

Desde 1824 se extienden los rumores sobre la participación de Michelena y Rocafuerte en la organización de una expedición de liberales españoles para derrocar al monarca español y de las intenciones de aquéllos de organizar, junto con la Gran Colombia, la invasión de Cuba e incluso de la propia Península, si España seguía manteniendo hacia ellos una política de hostilidad ${ }^{(51)}$. Estos informes que los diplomáticos españoles en-

(49) Ver la obra citada en nota 46.

(50) J. Fontana, La crisis del antiguo régimen, 1808-1833, BarceIcna, Crítica, 1983, pp. 201-202.

(51) O.J.E. Rodriguez, El nacimiento...., pp. 143-144. 
viaban a su gobierno desde París y Londres, eran en parte ciertos $\mathrm{y}$ en parte un medio de presión utilizado por los representantes mexicanos ante el primer ministro británico Canning, para que aceptara a las nuevas naciones $\left({ }^{52}\right)$, lo que finalmente hizo éste el 31 de diciembre de 1824, reconociendo la independencia de Argentina, Mexico y Colombia.

Todas las tentativas de incursión en las costas españolas que se intentaron organizar o que se llevaron a cabo desde Gibraltar por los liberales españoles, contaron desde entonces con la ayuda de los hispanoamericanos $\left({ }^{53}\right)$. Desde la existencia en 1827 de la junta Directiva del Alzamiento de España», que agrupaba en Londres a los liberales unidos en torno a Jose María de Torrijos, se entablaron negociaciones más formales con los funcionarios de la embajada de Mexico y con el ministro grancolombiano, José Fernández de Madrid, en las cuales acordaron, que si los liberales peninsulares y americanos colaboraban, lograrían destruir el despotismo absolutista, y que si esta unión no se lograba, España permanecería bajo la tiranía e Hispanoamérica seguiría estando sometida a continuas amenazas $\left.{ }^{54}\right)$.

Como resultado de estas conversaciones, Vicente Rocafuerte firmó el 25 de marzo de 1828, con Torrijos, Manuel Flores Calderón y Alvaro Flórez Estrada como delegados de la Junta de Londres, un documento en cuyo encabezamiento podía leerse: «Tratado celebrado en Londres entre la República de los Estados Unidos Mexicanos y la Junta Superior de la Nación Española libre e independiente», explicitándose a continuación que el objeto del mismo era fundar sobre bases sólidas e inalterables la independencia, tranquilidad y prosperidad de ambas naciones, asunto que estaba pendiente desde $1825\left({ }^{55}\right)$. En sus 12 artículos, los españoles se comprometían a aceptar la independencia de Mexico, a establecer iguales tratados con los demás Estados que fueron antes colonias, y a pacificar las relaciones entre la isla de Cuba y Mexico, retirando las tropas que no fuesen necesarias para la seguridad interior y exterior de la misma. Por su parte, el gobierno de Mexico, contraía la obligación de ayudar a la Junta en su lucha contra «el Tirano»

(52) A.G.S., Estado, legajo 8.187,

(53) Concretamente, en la expedición de los hérmanos Bazán en f $\epsilon$ brero de 1826. Es constante durante todos estos años, la denuncia de las autoridades absolutistas del refugio y ayuda que obtenían los españoles exiliados en la plaza inglesa de los barcos colombianos que se hallaban en la bahía.

(54) O.J.E. Rodriguez, El nacimiento..., p, 142 y nota 34.

(55) I.M. Zavala, Masones...., pp. 295-296. 
y de dar un empréstito de cinco millones de pesos cuando se rompieron las hostilidades.

Las dificultades internas de Mexico impidieron la ratificación del tratado, pero los contactos en Inglaterra prosiguieron, haciendo Torrijos y sus partidarios cuanto estuvo a su alcance para ayudar a los independentistas, que formaban parte de las mismas sociedades secretas, en el seno de la cuales siguieron formándcse planes insurreccionales conjuntos.

El más importante de ellos se formó en torno a la expedición que en el verano de 1829 envió Fernando VII para invadir Mexico: al mando del brigadier Barradas, salieron de Cuba más de 3000 hombres que desembarcaron en Tampico en julio de 1829, donde sufrieron una desastrosa derrota. Fue después de la misma cuando el gobierno español tuvo noticia de las actividades que habían desarrollado en torno a la misma los liberales mexicanos y españoles $\left.{ }^{56}\right)$. La propuesta la habían hecho los primeros a varios jefes militares españoles exiliados en Londres. Se trataba de la organización de un pronunciamiento, preparado desde Estados Unidos, con el objetivo de conseguir el exterminio o la deserción del ejército españcl destinado a Mexico, la insurrección de la isla de Cuba y la preparación desde ella de una expedición a España:

"Que se pondrá desde luego a su disposición un buque armado con once cañones, dejando a su buen juicio el calibre $\mathrm{v}$ demás pertrechos de guerra que ha de transportar dicho buque. Desde Inglaterra saldrá para Estados Unidos, donde hallará el dinero y protección que se necesiten para hacer la recluta sin obstaculo ninguno. Se le mostrará la proclama que debe aparecer al presentarse al frente del egercito invasor para que la examine, añada, quite o modifique según lo crea conveniente. Fl obieto de la empresa es la deserción del egercito español espedicionario o su exterminio. Logrado que sea, todos los Estados Unidos de América facilitarían a este Gefe cuantos medios necesite para volver sus armas contra la Habana, y desde allí intentar la revolución en España....».

El confidente que proporcionó la información de estos proyectos al embajador español en Londres, Cea Bermúdez, insistía en que había que vigilar a los negros, pues se sabía habían sido ganados muchos de ellos para la empresa, y la comparaba con la de marzo de 1826, cuando llegaron a Londres

(56) A.H.N., Estado, legajo 3.076: Informe proporcionado por un confidente al embajador español Cea Bermúdez, transmitido por éste el 16 de noviembre de 1829. 
«tres emisarios a concertar con algunos gefes españoles refugiados el plan de sublevar simultáneamente la Península y la Isla de Cuba bajo el grito de Libertad, pero que el plan del día se medita bajo el grito de independencia americana».

El informante especificaba además que existían contactos preparados en Cuba y tres individuos en la vanguardia expedicionaria «que se hallan iniciados en el plan, y que deben obrar en consecuencia». Aunque no tuvo efecto el pronunciamiento, sí que eran ciertas dos cosas: que los hispanoamericanistas habían perseguido con todas sus fuerzas la liberación de Cuba, y que la Junta de Torrijos había ayudado a «malograr la espedición contra Méjico», en palabras de Cea Bermúdez ${ }^{(57)}$.

Efectivamente, Torrijos y el coronel Epifanio Mancha habían enviado a través de Gorostiza, cartas a los oficiales que formaban parte de la expedición de Barradas, entre otros al hermano del último, Francisco de Paula Mancha, comandante interino de Caballería de las tropas que desembarcaron en Tampico, el cual, tras la capitulación, volvió a la Habana, según el otro Mancha "para llevar sus planes adelante» $\left({ }^{58}\right)$. Los informes recibidos de Inglaterra por el gobierno español al respecto, provocaron su detención y la culpabilidad de su hermano, que reprochaba a Torrijos y Gorostiza el no buscar los medios para salvarle. Epifanio Mancha siguió sin embargo al lado de Torrijos hasta el final de su tentativa insurreccional $\left({ }^{59}\right)$.

Fue con Gorostiza, liberal exaltado durante el trienio liberal español y nuevo ministro mexicano en Inglaterra tras la marcha de Rocafuerte, con quien la Junta de Londres siguió las relaciones durante 1829 y 1830 , recibiendo del gobierno de Mexico cien mil reales "por los buenos servicios que había hecho por la República» ${ }^{\left({ }^{80}\right)}$.

Los contactos fueron sin embargo decayendo al buscar cada vez más el gobierno mexicano la negociación con Madrid del reconocimiento formal de la independencia. Había además una cuestión de fondo que explica este enfriamiento entre

(57) Idem

(58) A.H.N., Estado, legajo 3.075: informe del confidente de Cea Bermúdez, José Baiges, el 31 de mavo de 1830. El mismo documento en A.G.S., Estado, legajo 8.199, folio 67.

(59) Perteneció al núcleo dirigente de la Junta de Gibraltar de Torrijos, participando en la organización del fracasado pronunciamiento en Málaga en diciembre de 1831. Expulsado de Gibraltar, pasó a Marsella a principios de 1832 . Sobre el personaje, que era padre de la Teresa Mancha del poeta Espronceda, véase $\mathrm{R}$. Marrast, José de Espronceda...., pp. 177-181.

(80) Informe citado en nota 57. 


\section{Constitucionalismo, Estrategia Insurreccional}

liberales exiliados españoles e independentistas hispanoamericanos: la ambiguedad que mantuvieron los primeros respecto a la comprensión del fenómeno de la emancipación, puesta de relieve en la correspondencia sostenida por Torrijos y el general Palarea con Gorostiza, en octubre de 1829. Los españoles equiparaban la suerte de España a la de Mexico, basando su mútuo interés en la lucha contra el despotismo y la tiranía, para consolidar la libertad de España y la independencia americana, pero afirmaban no querer inmiscuirse en los asuntos interiores de Mexico: «Si bien sincera y cordialmente simpatizamos con la independencia de América, no nos corresponde, como españoles intervenir en ella, sino dar libertad a nuestra patria y consolidar así la independencia y prosperidad de ambos países». Gorostiza reprochó en su respuesta las contradicciones de su anticolonialismo, acusándoles de contemplar la independencia de Hispanoamérica como algo secundario y de ser, en definitiva, más antiabsolutistas que anticolonialistas, dejando «a un lado sus opiniones liberales cuando se trata de la independencia de las Américas y, principalmente, de Mexico» ( ${ }^{(61)}$.

Cuando la Junta de Londres intentó a principios de 1830 establecer nuevos acuerdos con la República de Mexico, ésta contestó que

«en atención que mediaba relaciones entre los gobiernos de Francia e Inglaterra para que estos gobiernos intercediesen con el rey de EsDaña para aue reconociese la indedependencia.... la República no podía proteger lo aue solicitaban, pero que siempre que se desviasen las relaciones citadas, entonces resolvería» ${ }^{\left({ }^{62}\right.}$ ).

No se produjo una ruptura, pues como explicaba en mayo de 1830 Gorostiza al liberal español Alcalá Galiano, podía llegar el caso de seguir necesitándose, justificando a continuación la ayuda económica prestada hasta entonces, pero aclarando seguidamente, que «su gobierno no podía dar más ni proteger la revolución de España. Si Torrijos invierte esta cantidad para revolucionar, será obra suya» ${ }^{(33)}$. Del mismo modo, cuando Éspoz y Mina, en 1831, a través de una comisión de emigrados españoles estabelecida en Nueva Orleans, solicitó un préstamo para la empresa revolucionaria al gobierno de Mexico, éste

(61) Tomo las citas y comentarios del artículo ya citado de J.R. Aymes, "El anticolonialismo español....».

(62) A.H.N., Estado, legajo 3.076. Informes de Cea Bermúdez sobre los contactos entre Torrijos e Gorostiza.

(63) Informe citado en nota 57. 
contestó en los mismos términos, que no tenía fondos de los que disponer para la causa española $\left({ }^{64}\right)$.

He presentado, en esta breve síntesis, a través de dos episodios claramente representativos de lo que podemos llamar las relaciones exteriores del liberalismo español, la dimensión internacional del movimiento liberal revolucionario de la época, que tenía como ejes comunes el modelo insurreccional como estrategia y la Constitución como objetivo político y programa superador del Antiguo Régimen.

(64) Espoz y Mina, Memorias, 147, p. 212. 